NASA-CR-205169

Meteorol. Atmos. Phys. 51, 239-258 (1993)

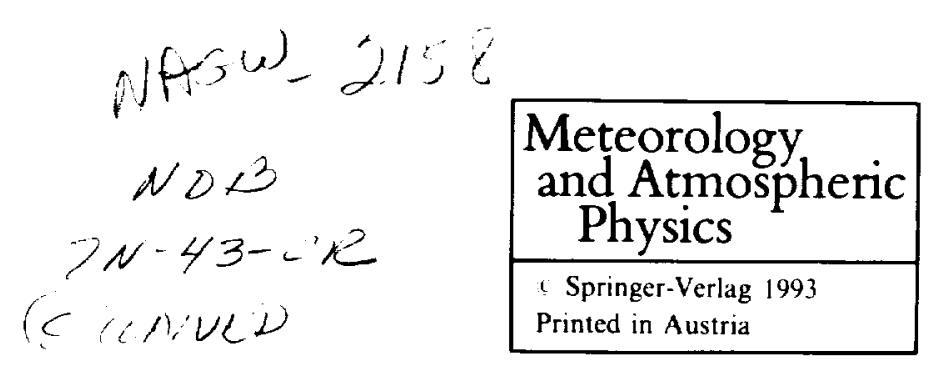

$551.583: 551: 579.3(988)$

Cooperative Institute for Research in Environmental Sciences, University of Colorado, Boulder, Colorado, U.S.A.

\title{
Climate Sensitivity Studies of the Greenland Ice Sheet Using Satellite AVHRR, SMMR, SSM/I and In Situ Data
}

\author{
K. Steffen, W. Abdalati, and J. Stroeve \\ With 16 Figures
}

Received January 25, 1993

Revised February 8, 1993

\begin{abstract}
Summary
The feasibility of using satellite data for climate research over the Greenland ice sheet is discussed. In particular, we demonstrate the usefulness of Advanced Very High Resolution Radiometer (AVHRR) Local Area Coverage (LAC) and Global Area Coverage (GAC) data for narrow-band albedo retrieval. Our study supports the use of lower resolution AVHRR (GAC) data for process studies over most of the Greenland ice sheet. Based on LAC data time series analysis, we can resolve relative albedo changes on the order of $2-5^{\%} \%$ In addition, we examine Scanning Multichannel Microwave Radiometer (SMMR) and Special Sensor Microwave Imager (SSM/I) passive microwave data for snow typing and other signals of climatological significance. Based on relationships between in situ measurements and horizontally polarized 19 and $37 \mathrm{GHz}$ observations, wet snow regions are identified. The wet snow regions increase in aerial percentage from $9^{\circ}$ of the total ice surface in June to a maximum of $26 \%$ in August 1990. Furthermore, the relationship between brightness temperatures and accumulation rates in the northeastern part of Greenland is described. We found a consistent increase in accumulation rate for the northeastern part of the ice sheet from 1981 to 1986.
\end{abstract}

\section{Introduction}

\subsection{Greenland Ice Sheet - Overview}

The Greenland ice sheet is one of the major ice sheets in the world. It is the largest one in the Northern Hemisphere and is generally thought to have survived throughout the Quaternary. The ice sheet presently plays an important role in the hemispheric circulation through its topography and strong temperature gradient towards the northwestern Atlantic. The present ice sheet has a surface area of $1.75 \cdot 10^{6} \mathrm{~km}^{2}$ and a volume of $2.65 \cdot 10^{6} \mathrm{~km}^{3}$. These correspond to 11 and $8 \%$ of the global glacier surface area and the ice volume, respectively (Ohmura et al., 1991). The ice volume is also equivalent to $6.7 \mathrm{~m}$ of water relative to the present global sea level. The ice sheet has a typical shield shape climbing relatively steeply from sealevel to $1000 \mathrm{~m}$ and then gently to the highest point of $3210 \mathrm{~m}$ a.s.l. at $72.3^{\circ} \mathrm{N}$ and $38.0^{\circ} \mathrm{W}$, where the thickness of ice is estimated at about $3000 \mathrm{~m}$. The average thickness of the ice sheet is $1515 \mathrm{~m}$.

The Greenland ice sheet is a remnant of the Pleistocene ice sheet. During the last ice age the volume was estimated at 2.92 to $5.59 \cdot 10^{6} \mathrm{~km}^{3}$ (Ohmura et al., 1991), suggesting that the surface altitude was higher in the past. Presently the equilibrium line of the ice sheet lies at $1800 \mathrm{~m}$ a.s.l. at the southern end, and it descends to $750 \mathrm{~m}$ a.s.l. in the northern Greenland (Ambach and Kuhn, 1985). The accumulation and ablation area occupy 82 and $18 \%$, respectively. Within the accumulation area the dry snow line is found at $3100 \mathrm{~m}$ in the south descending to $1650 \mathrm{~m}$ in the north, with the surface area of the dry snow zone being approximately $50 \%$ of the entire ice sheet. 


\subsection{Greenland Ice Sheet-Climatology}

Snow and ice are key variables in the global climate system. They can influence the global heat budget through their regional feedback mechanism in the varying exchange of heat, moisture and momentum between the surface and the atmosphere (Dickinson et al., 1987). Therefore, accurate information on cryospheric variations (e.g. large scale surface albedo increases or decreases due to change in dry snow area extent) are essential for the prediction of future climate change. Information on the response of the ice sheet to climate warming is of crucial importance for reliable projection of future sea level. As the Greenland ice sheet is located in a relatively warm climate, it is particularly vulnerable to climate change. Present computer model simulations of the greenhouse scenario predict a regional cooling for the Greenland ice sheet, contrary to the general warming trend over the Arctic sea ice areas (Manabe et al., 1992). Trends for the annual temperature computed from land surface stations for the period 1961 to 1990 show a slight cooling for the southern half of Greenland (Chapman and Walsh, 1993). However, our present knowledge of the mass and energy exchange, and its sensitivity to environmental conditions, is insufficient to make reliable quantitative estimates of future changes associated with the greenhouse warming. An observed $0.23 \mathrm{~m} /$ year thickening of the Greenland ice sheet south of $72^{\circ} \mathrm{N}$ was reported by Zwally (1989) based on satellite radar altimeter measurements. The northern part of the ice sheet was not covered by satellite altimeter measurements and at this point we don't know if the Greenland ice sheet north of $72^{\circ} \mathrm{N}$ is growing or shrinking.

Annual total precipitation and annual accumulation on the Greenland ice sheet were evaluated by Ohmura and Reeh (1991). The analysis is based on accumulation measurements of 251 pits and cores obtained from the upper accumulation zone and precipitation measurements made at 35 meteorological stations in the coastal region. The mean annual precipitation for all of Greenland was found to be $340 \mathrm{~mm}$ water equivalent, with an increasing gradient from north to south. The amount of precipitation is regulated primarily by atmospheric conditions, such as stability, watervapor content and circulation. The winter circulation is strongly dominated by two semi- permanent cyclones, the Baffin Bay low to the west and the larger Icelandic low to the southeast. The ice sheet is located under the weak saddle between the two depressions. The summer circulation is dominated by the pressure ridge extending from the northeast towards the center of the ice sheet. Changes in the surface radiation balance and/or in the cloud amount over the ice sheet due to global climate change may alter the overall pressure distribution and consequently the precipitation. It is beyond the scope of this paper to derive precipitation amounts, but the aerial extent of dry snow area and its seasonal and annual variations as derived from satellite data will help to understand the present situation.

\subsection{Greenland Ice Sheet-Research Camp}

Scientists from the Swiss Federal Institute of Technology (ETH) in Zürich established a permanent research camp at the equilibrium line of the Greenland ice sheet near Jakobshavn $\left(69^{\circ} 34^{\prime} \mathrm{N}\right.$, $49^{\circ} 17^{\prime} \mathrm{W}$ ) in spring of 1990 (Fig. 1). Climatological measurements were carried out to study the energy exchange and the mass balance above, at, and below the ice surface during April-September of 1990 and 1991. Furthermore, the structure of the atmospheric boundary layer within the katabatic wind regime on the ice sheet was recorded with daily radiosonde profile measurements. Preliminary results from the two field seasons are summarized in progress reports (Ohmura et al., 1991, 1992). The research station has been transferred in summer 1992 to the University of Colorado at Boulder to continue the field experiments for three additional seasons.

Micro-climatological measurements at a single point are necessary and essential for the study of the magnitude of the different energy fluxes such as the turbulent fluxes and radiation balance at the ice sheet surface. However, a single point measurement is not sufficient to discuss the climatology of the entire Greenland ice sheet. Therefore, we propose the use of multispectral satellite data to derive certain surface parameters which are relevant to the surface climatology. The purpose of this paper is to demonstrate the feasibility of satellite remote sensing as a technique for climate studies over large homogeneous snow and ice covered areas. The ultimate goal of the project is the statistical analysis of the regional and seasonal 


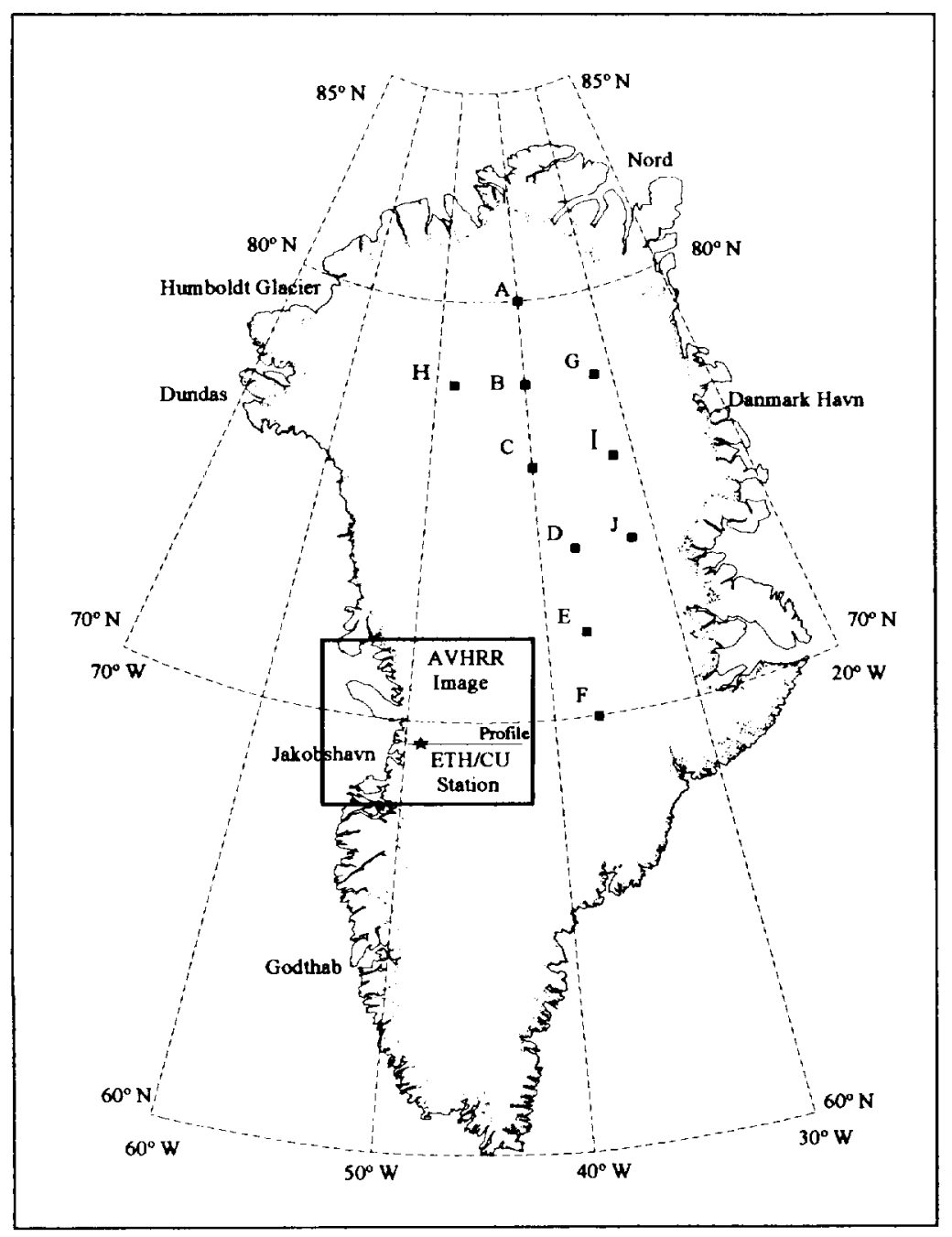

Fig. 1. Overview of the Greenland ice sheet. The outline of the ice sheet is shown with a dotted line, and the land is depicted with a solid line. The location of the joint research camp of the Swiss Federal Institute of Technology and the University of Colorado at Boulder is shown at the west side of the ice sheet near the coastal village of Jakobshavn. The labels $A$ through $K$ give the locations of the SMMR brightness temperature time series as given in Fig. 14 and 15 variations of surface parameters. This statistical analysis over a period of ten years is needed to improve the present knowledge and understanding of the Greenland ice sheet surface climatology.

\section{Method}

\subsection{Multispectral Satellite Data}

Past and ongoing research have shown that several polar surface properties can be mapped through a combination of multispectral satellite and aircraft data (Steffen et al., 1993; Haefliger et al., 1993; Williams et al., 1991). These properties include: spectrally integrated surface albedo, surface temperature, shortwave and longwave radiation balance, and snow properties. All of these parameters can be linked to the surface energy balance. The Greenland ice sheet, due to its large size and homogeneous surface, is an ideal test area for the development of remote sensing techniques in climate research. Unlike sea ice and land areas, the three major surface types of the ice sheet (glacier ice, wet snow, and dry snow) extend over several tens of kilometers at a minimum, which makes the application of low resolution satellite data feasible for surface type classification.

The types of satellite imagery used for this study cover a range of spatial resolutions and wavelengths. For the visible and thermal infrared wavelengths we have used Advanced Very High Resolution Radiometer (AVHRR) Local Area Coverage (LAC: $1.1 \mathrm{~km}$ at swath nadir) and Global Area Coverage (GAC: $4 \mathrm{~km}$ at swath nadir) data. For the passive microwave region, Nimbus-7 Scanning multifrequency microwave radiometer (SMMR) data (10/25/80-8/20/87), and DMSP 


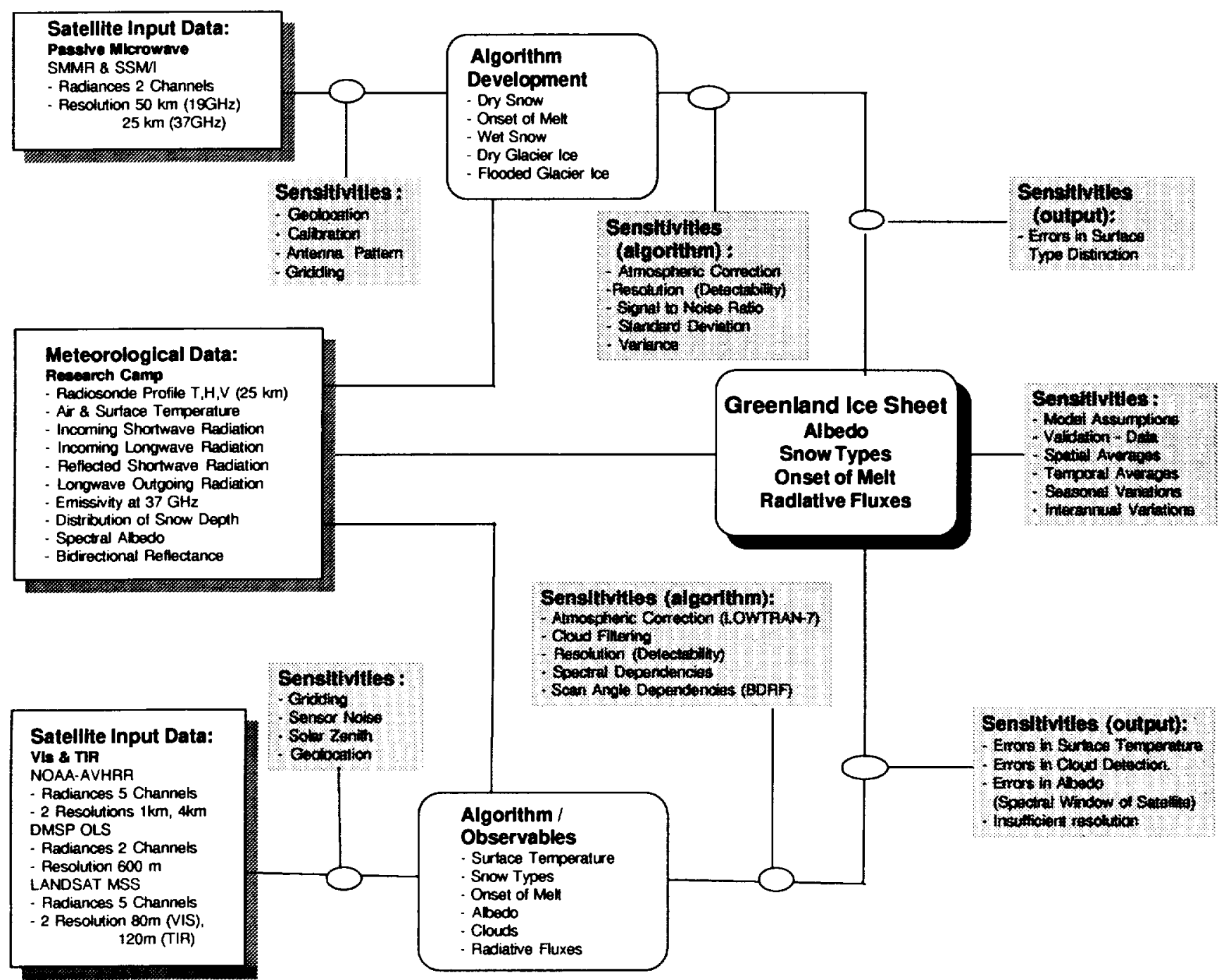

Fig. 2. Processing of multi-spectral satellite data in combination with in situ measurements for the retrieval of the surface parameters relevant to climate process studies

special sensor microwave imager $(\mathrm{SSM} / \mathrm{I})$ data $(7 / 9 / 87-9 / 30 / 90)$ were used. They are presently available for both polar regions, including the Greenland ice sheet, on CD-ROM from the National Snow and Ice Data Center (NSIDC), Boulder, Colorado.

In order to retrieve surface parameters relevant for climate process studies from satellite imagery, a number of sensitivity analyses and intercomparisons with ground measurements are needed. These are described below (Fig. 2).

\subsection{Processing of AVHRR Data}

The AVHRR data were received as raw data that have been quality controlled and assembled into discrete data sets (level $1 \mathrm{~b}$ data) at the Naval Oceanic Atmospheric Research Laboratory (NOARL). AVHRR LAC and GAC channel 1 $(0.58 \mu \mathrm{m}-0.68 \mu \mathrm{m})$ and $2(0.725 \mu \mathrm{m}-1.10 \mu \mathrm{m})$ images have been calibrated over the entire Greenland ice sheet using pre-launch calibration coefficients to obtain percent albedo values. The calibration technique follows the description given in the NOAA users guide (Kidwell, 1991) and includes the non-linear corrections. In order to correct for the geometric distortions caused by the curvature of the earth and the scanning geometry the images have been geo-registered and mapped to a polar stereographic projection using a navigation code developed by Baldwin et al. (1993). The accuracy of the navigation routine is at most 
6 to $8 \mathrm{~km}$ due to errors in the time tags. The images have been fitted to a map grid to reduce this error to less than 1 pixel. The CPU times necessary to calibrate and navigate the LAC and GAC data for the entire Greenland ice sheet are 5 min for a GAC image $(325 \times 625$ pixels $)$ and 84 min for a LAC image $(1500 \times 2500$ pixels $)$ on a IBM 6000 workstation. On a SUN II workstation $13 \mathrm{~min}$ for GAC and $188 \mathrm{~min}$ for LAC are needed to process the satellite imagery.

Our present computing facility does not permit the processing of a large number of LAC scenes due to extensive computing time necessary to calibrate and navigate the AVHRR LAC images for the entire Greenland ice sheet. Thus, it is desirable to use the GAC images for long time series analysis. In section 3 we present a pilot program to test the feasibility of using AVHRR GAC images for long term climate studies over the Greenland ice sheet.

\subsection{Processing of SMMR and SSM/I Data}

The SMMR is a ten-channel, five frequency linearly polarized passive microwave radiometer system. The instrument measures surface brightness temperatures at $6.6,10.7,18.0,21.0$ and $37.0 \mathrm{GHz}$. Vertical and horizontal polarization are provided for each frequency. The SSM/I operates at four frequencies, namely $19.35,22.24,37.0$, and $85.0 \mathrm{GHz}$. Both polarizations are provided for each frequency except $22.24 \mathrm{GHz}$. For this study we used the 19 and $37 \mathrm{GHz}$ frequencies which have effective field of view dimensions of $69 \times 43 \mathrm{~km}$ and $37 \times 28 \mathrm{~km}$, respectively (along track $\times$ cross track). The SMMR and SSM/I data provided by NSIDC are gridded in polar stereographic projection in $25 \times$ $25 \mathrm{~km}$ grid cells.

The passive microwave data are read from the CD-ROM, and all points within the rectangle whose edges contain the outermost limits of the Greenland boundary are extracted. Then the ocean mask (which is provided on each CDROM) is applied. This procedure is followed for all of the available dates, and it yields a set of images $60 \times 109$ pixels in size for each channel and each day of SSM/I and SMMR coverage. A total of 1611 images for each SMMR channel and 1186 images for each SSM/I channel have been extracted.

Some applications, such as snow mapping (described in section 3.2) or SMMR/SSM/I cor- relations which are described below, require that the data be left in image format. For such applications an ice mask was developed from a vector file of the ice sheet boundaries which was digitized from the Geological Survey of Greenland (GGU) geological map (scale $=1: 250,000$ ). This mask is applied to the images and the result was a set of images of the Greenland ice sheet with no landcontaminated pixels.

Other applications such as time series investigations require that data points from the same location(s) be extracted from all of the images. The first such application is the retrieval of time series of brightness temperatures along a horizontal transect across Greenland. The transect chosen in the first stage of the data analysis is the one that passes through the ETH/CU research station (Fig. 1). In addition to providing information about the brightness temperatures along a west/ east profile across the ice sheet, this time series provides a means of identifying days of bad data. The brightness temperatures between $318-325^{\circ} \mathrm{E}$ longitude are relatively stable with little fluctuation. Consequently, days that show very high deviation from the normal (greater than 4 sigma) in this longitude range are flagged as "bad" days, and are linearly interpolated from the nearest "good" days.

From the transect, the pixel that corresponds to the station location is extracted, and a time series of data specifically for the station is produced. In addition, the horizontally polarized gradient ratio is calculated using the following formula:

$\mathrm{GR}=(19 \mathrm{H}-37 \mathrm{H}) /(19 \mathrm{H}+37 \mathrm{H})$

where 19 and 37 correspond to the channel frequencies in $\mathrm{GHz}$, and $\mathrm{H}$ indicates horizontal polarization. Similar time series can be produced for any location on the ice sheet, but the climate station is chosen initially so that comparisons to in situ data can be made.

One final item in the processing of the passive microwave data pertains to the relationships between SMMR and SSM/I data. An extended time series is important for the assessment of climatological trends, but in order to effectively combine the SMMR and SSM/1 data sets, a comprehensive understanding of how the two are related must be obtained. Figure 3 shows the relationship between the 4 common channels on the two instruments for the overlapping days of 

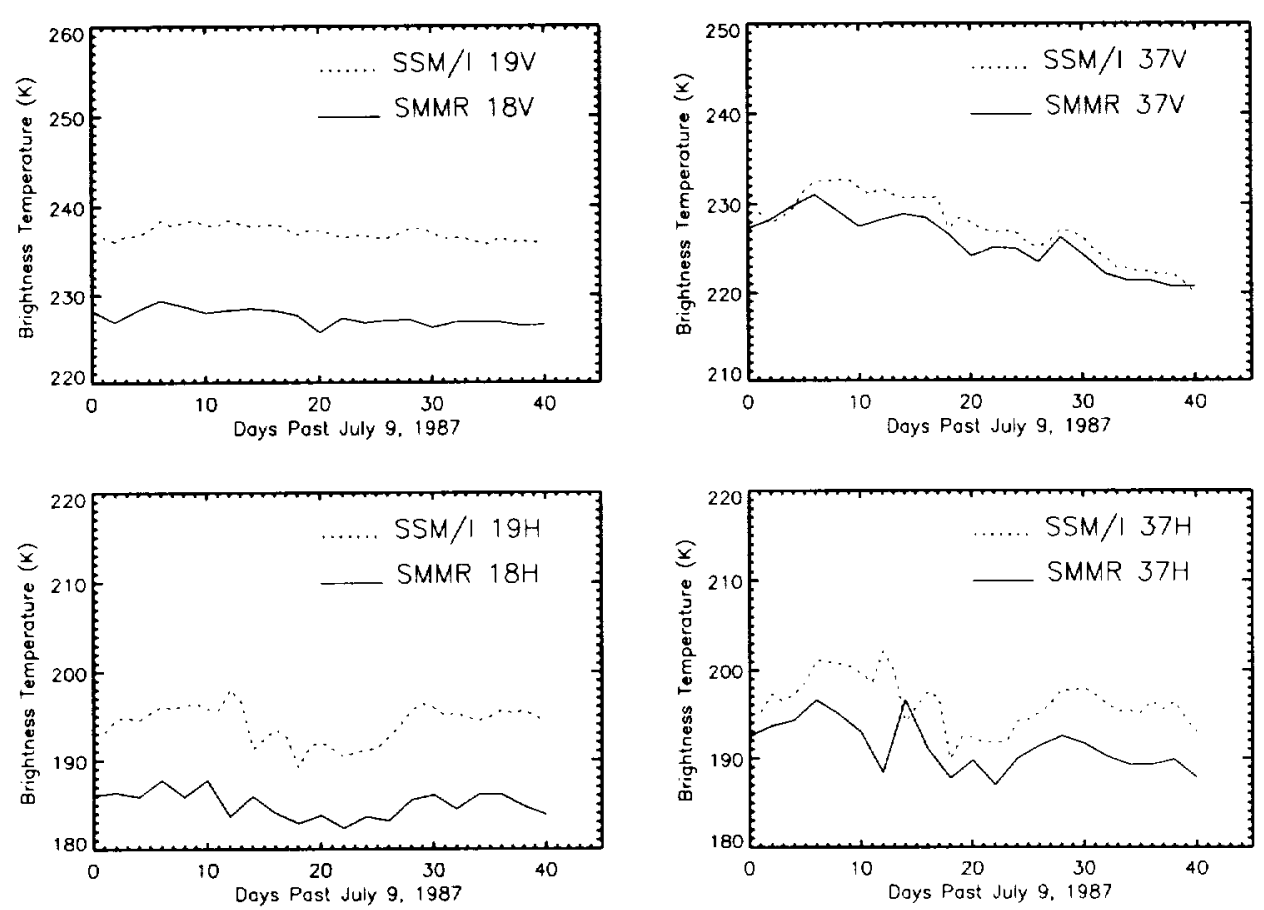

Fig. 3. SMMR and SSM/I brightness temperatures for the overlapping days in 1987 (July 9-August 20 ) at $72^{\circ} \mathrm{N}$ and $37^{\circ} \mathrm{W}$ longitude

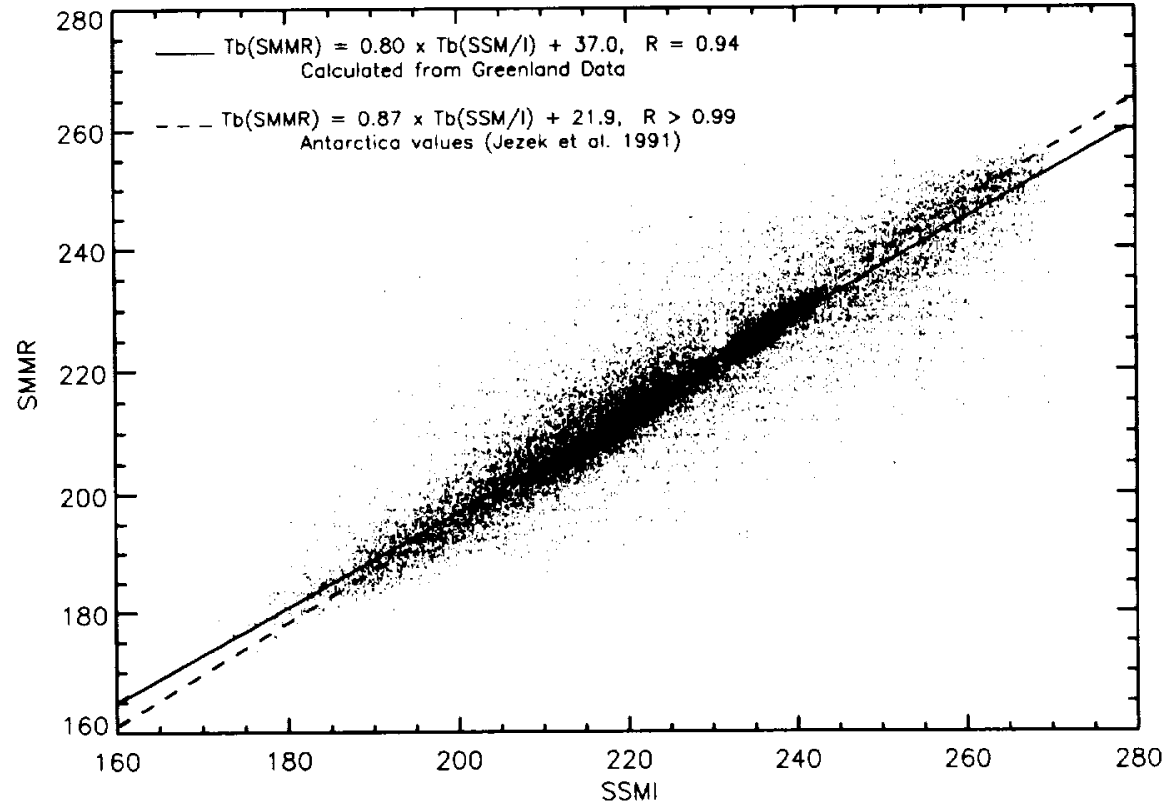

Fig. 4. Relationship between S MMR and $S S M / I$ data over the entire ice sheet for the full period of overlapping coverage operation in the highest area of the ice sheet $\left(72^{\circ} \mathrm{N}\right.$ and $37^{\circ} \mathrm{W}$ ). A large discrepancy (nearly 10 degrees consistently) is apparent between the $19 \mathrm{GHz}$ SSM/I channels and the $18 \mathrm{GHz}$ SMMR channels. Similar discrepancies, though not as pronounced, exist for the $37 \mathrm{GHz}$ channels.
These relationships were addressed for Antarctica by Jezek et al. (1991), but they have not yet been defined for the Greenland ice sheet. For all of the overlapping days, July 9, 1987 through August 20, $1987, \mathrm{SSM} / 119 \mathrm{GHz}$ vertically polarized brightness temperature measurements are compared to 
the corresponding SMMR observations $(18 \mathrm{GHz}$ vertically polarized), and the relationships are assessed. The results, which correspond well to Jezek et al. (1991) results are shown in Fig. 4. The small discrepancy can most likely be credited to the fact that Antarctica has much colder regions than Greenland. Consequently, the data points span a much broader range of temperatures, so the behavior of the correlation curve is better defined at the low end. Furthermore there is simply more data from Antarctica because of its size. The similarity between the two regression lines, however is encouraging.

Based on this comparison, the SMMR time series can be extended to include the SSM/I data, for a data set that currently spans over 13 years. Similar relationships need to be determined for the other channels.

\section{Results}

\subsection{Narrow-Band Albedo of Snow}

The variation of solar radiation absorbed and reflected by the earth is a key factor in the understanding of climate change. If the solar radiation reflected by the earth were to increase, a trend toward the extension of the winter season would result, as can be shown in a simple energy feedback mechanism (Budyko, 1974). The snow
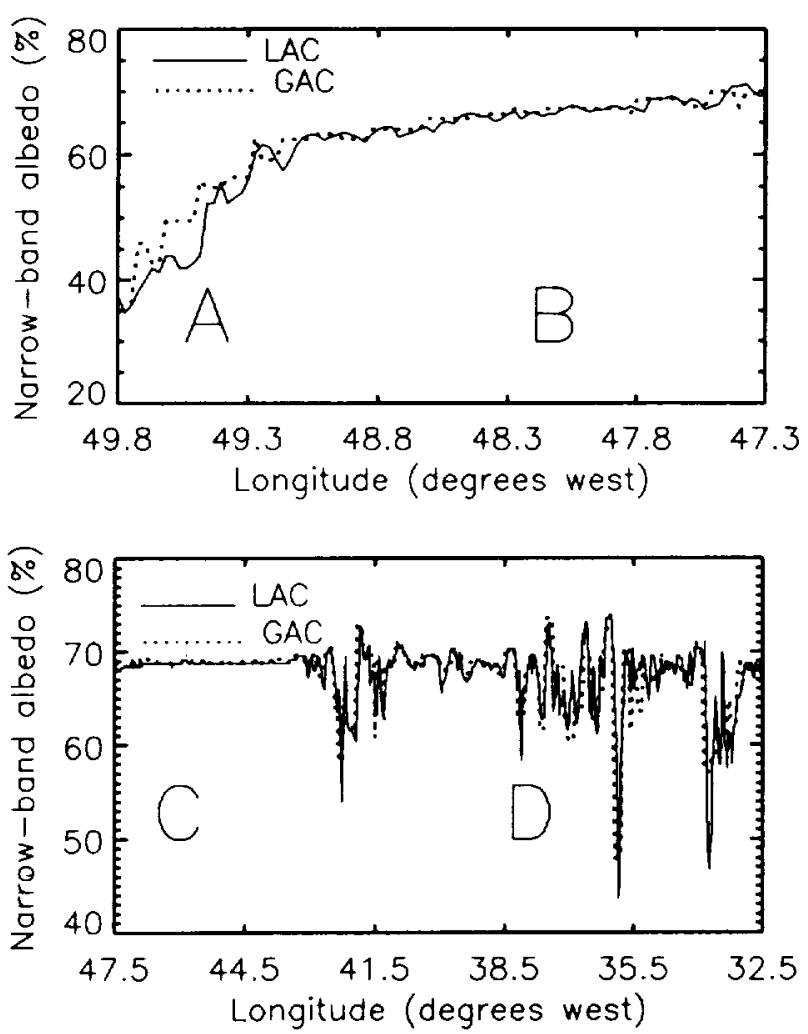

Fig. 6. West-east transect plots of narrow-band planetary albedo $(0.58-0.68 \mu \mathrm{m})$ for AVHRR Local Area Coverage (LAC: dotted curve) and Global Area Coverage (GAC: line curve) data at $69.6^{\circ} \mathrm{N}$ of the Greenland ice sheet. Four regions for June 06, 1990 are represented. Region A shows the bare ice, region $B$ the wet snow, region $C$ the dry snow, and region $\mathrm{D}$ the clouds

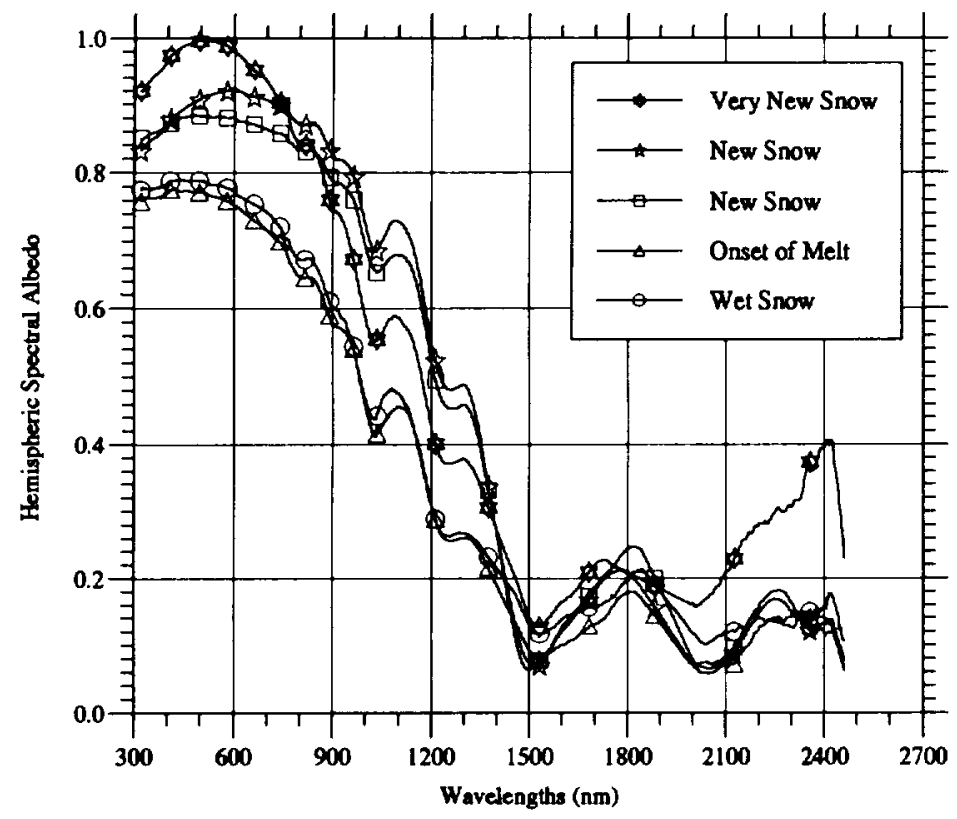

Fig. 5. Hemispheric spectral albedo for very new snow (a few hours old), new snow (1-2 days old), onset of melt, and melting snow surface in the spectral range $300-2500 \mathrm{~nm}$ measured at the $\mathrm{ETH} / \mathrm{CU}$ research camp in 1991 
cover is one of the most reflective naturally occurring materials, and therefore, an understanding of its visible solar reflectance is of great importance. The spectral albedo of different snow types at the ETH/CU research camp was measured for the purpose of calibrating and interpreting satellite derived values (Fig. 5). All measurements were carried out at solar zenith angles between $50^{\circ}$ and $68^{\circ}$. The snow grain diameter varied for the different measurements: very new snow $0.5 \mathrm{~mm}$; new snow $0.1-0.2 \mathrm{~mm}$; onset of melt and wet snow $1-5 \mathrm{~mm}$.

AVHRR LAC and GAC data were processed as described in section 2.2 to study the differences in pixel resolution for albedo retrieval over the ice sheet. Figure 6 shows transect plots of the planetary albedo values for both the LAC and GAC channel 1 $(0.58-0.68 \mu \mathrm{m})$ across the ice sheet at $69.6^{\circ} \mathrm{N}$. Four different regions can be distinguished:

\section{Region A: Bare Ice and Slush}

In this region the majority of the snow has melted and bare ice remains. Surface lakes tend to form on top of the bare ice, and some slush also exists. The agreement between the LAC and GAC images is low in comparison to the dry snow regions. Such a result is expected because the melt lakes are within the $1 \mathrm{~km}$ foot-print of the LAC data but the GAC footprint contains information from the surrounding area as well (Table 1).

\section{Region B: Wet Snow}

In the wet snow region, the agreement between the LAC and GAC data is much improved. Although, small scale variation is not detected with the GAC data, the general gradual increase of albedo is well represented (Table 1).

Table 1. Statistical Results of the Comparison Between LAC and GAC Data from June 06, 1990. Values are given for a region $300 \mathrm{~km}^{2}$ region

\begin{tabular}{llll}
\hline Region & $\begin{array}{l}\text { Mean } \\
\text { difference } \%\end{array}$ & $\begin{array}{l}\text { Std dev of } \\
\text { difference }\end{array}$ & Correlation \\
\hline Bare ice & -2.05 & 3.06 & 0.890 \\
Wet snow & -0.16 & 0.89 & 0.970 \\
Dry snow & -0.04 & 0.26 & 0.998 \\
Clouds & 0.06 & 2.21 & 0.997
\end{tabular}

\section{Region C: Dry Snow}

Over dry snow where the albedo remains relatively constant, the agreement between the LAC and the GAC images are very high, with mean differences practically zero. In this region the albedo is very homogeneous and thus very little difference between the two resolutions is expected (Table 1).

\section{Region D: Clouds}

Detection of clouds tends to be difficult since cloud reflectance is similar, if not identical, to snow reflectance. However, thick overcast regions show noticeable fluctuations in reflectance $(5 \%)$. In these regions the agreement between the LAC and the GAC images decreases slightly (Table 1), but due to the large size of the cloud features $(4 \mathrm{~km}$ or larger) the GAC data is able to detect the slight variation in reflectance due to the presence of clouds as well as the larger decrease in reflectance from the cloud shadows. The ability of the GAC data to detect the cloud shadows could be a useful tool in cloud discrimination over the Greenland ice sheet.

Thus, the same information for wet snow, dry snow, and clouds can be obtained by using either high or low resolution data. Using the GAC data during summer months, when the melt region is relatively large, should be adequate. When. the melt season is just beginning, the lower resolution data will not be able to accurately detect the melting since the pixel will be contaminated by dry snow. Higher resolution data such as LAC will be needed at the margin of the ice sheet in such cases. In addition, to study the surface lakes that form during the melting season, high resolution data with pixel size less than $2 \mathrm{~km}$ (average lake diameter) will also be needed.

To obtain snow surface albedo maps it is necessary to correct the AVHRR satellite data for the intervening atmosphere. Such a correction can be accomplished using a linear relationship between clear sky planetary albedo and surface albedo (Koepke, 1989), or by using a radiative transfer model, such as LOWTRAN or 5S, to correct for scattering and absorption. Although presently there is no consensus among scientists as to which atmospheric radiative transfer code is best, most codes tend to disagree only for large optical depths of aerosols and large off-nadir angles $\left(60^{\circ}\right.$ or more) (Royer et al., 1988). The $5 \mathrm{~S}$ code developed 
by Tanre et al. (1990) provides reasonably accurate atmospheric modeling and surface reflectance retrieval (Teillet, 1992). The overall scheme involves correcting the narrow-band planetary albedo as viewed by the sensor to the narrow-band surface albedo, taking into account illumination, sensor view angle, and atmospheric effects.

To run the code, illumination and observation geometries for each pixel are provided as input. The water vapor input can be calculated from the AVHRR channels $4(10.30-11.30 \mu \mathrm{m})$ and 5 $(11.50-12.50 \mu \mathrm{m})$ or it can be provided by radiosonde data that has been collected at the ETH/ CU camp during the summers of 1990 and 1991 (Haefliger et al., 1993). Radiosonde data are also available from the summit of the Greenland ice sheet and from the coastal station Gothavn and will serve to derive an "average atmosphere" for the data available in 1990 and 1991. Further parameterization is needed to extrapolate for other years. The ozone concentration is taken to be that of subarctic summer. Aerosol content can vary significantly in Arctic regions (Lindsay and Rothrock, 1993) and can result in large errors in deriving the surface reflectance. Unfortunately, optical depths of aerosols over the Greenland ice sheet are not known and standard atmosphere assumptions must be made. Using the $5 \mathrm{~S}$ code, it is possible to retrieve surface reflectance by the following expression:

$$
\begin{aligned}
\rho_{i} & =100 \frac{\left(A_{i}+B_{i}\right)}{\left(100+\left(A_{i}+B_{i}\right) S_{i}\right)} \\
A_{i} & =\frac{\left(\rho_{i}^{o} d_{s}^{2}\right)}{\tau_{g} \tau_{s} \tau_{v} \cos \theta_{s}}, \quad B_{i}=\frac{\left(1-100 \rho_{a r m}\right)}{\tau_{s} \tau_{v}}
\end{aligned}
$$

where the index $j$ stands for the AVHRR channel $(i=1,2)$.

$$
\begin{aligned}
\rho_{i}= & \text { surface reflectance for channel } 1 \text { or } 2 \text { in } \\
& \text { percent } \\
\rho^{o}= & \text { reflectance at the sensor } \\
\rho_{a t m}= & \text { atmospheric reflectance } \\
S= & \text { atmospheric spherical albedo } \\
\tau_{g}= & \text { total gas transmittance } \\
\tau_{s}= & \text { total scattering transmittance in solar } \\
& \text { direction } \\
\tau_{v}= & \text { total scattering transmittance in sensor } \\
& \text { direction } \\
d_{s}= & \text { solar distance } \\
\theta_{s}= & \text { solar zenith angle. }
\end{aligned}
$$

Table 2. Input Parameters for the $5 S$ Code Run for the Location of the ETH/CU Camp, May 23, 1991

$\begin{array}{ll}\text { Solar zenith angle } & 49.0^{\circ} \\ \text { Sensor zenith angle } & 29.40^{\circ} \\ \text { Solar azimuth angle } & 285.57^{\circ} \\ \text { Sensor azimuth angle } & 243.69 \\ \text { Atmospheric profile } & \text { (i) } \mathrm{H}_{2} \mathrm{O}=0.62 \mathrm{~g} \mathrm{~cm}^{-2} \\ & \text { (ii) } \mathrm{O}_{3}=\text { subarctic summer } \\ \text { Aerosol model } & \text { Continental } \\ \text { Aerosol level } & \text { Visibility }=8 \mathrm{~km} \\ \text { Spectral bands } & \text { NOAA-11 AVHRR channel 1 } \\ \text { Surface reflectance } & \text { Dry snow }\end{array}$

These quantities, which are necessary to calculate the surface reflectance, are obtained by running the $5 \mathrm{~S}$ code.

A three day time series for the AVHRR LAC channel 1 was atmospherically corrected using the in situ radiosonde profile data (See Table 2 for $5 \mathrm{~S}$ inputs). Figure 7 illustrates the temporal changes of narrow-band surface albedo for the dates May 23, June 01, and June 08, 1991, along a transect at $69.6^{\circ} \mathrm{N}$ (see also Fig. 1). This time series shows a continual decrease in albedo over time. On May 23,1991 , the snow cover was dry and the land was also covered by snow with many rocky areas showing through. By June 01, melting had occurred and the surface reflectance dropped considerably, and by June 08 the reflectance has decreased further by $5 \%$. The ability of the sensor to detect melt enables us to determine the aerial extent of the transition regions along the perimeter of the ice sheet. Figure 8 shows the AVHRR channel 1 imagery for the Jakobshavn area on June 8, 1991 (see also Fig. 1 for location). Cloud shadows running north-south on the left side of the image (snow covered ice sheet) can be identified. The snow free areas of the ice sheet along the margin (bare ice) stand out against the higher reflectance of wet snow areas.

The narrow-band surface albedo as derived from AVHRR channel 1 and corrected with the $5 S$ radiative transfer model for atmospheric scattering, and absorption was compared with in situ measurements at the ETH/CU station. The date used for this intercomparison is 23 May 1991 under clear sky conditions. The in situ hemispheric spectral albedo, integrated over the wavelength region $580-680 \mathrm{~nm}$, is $91.6 \%$, and the narrowband albedo derived from AVHRR channel 1 is 


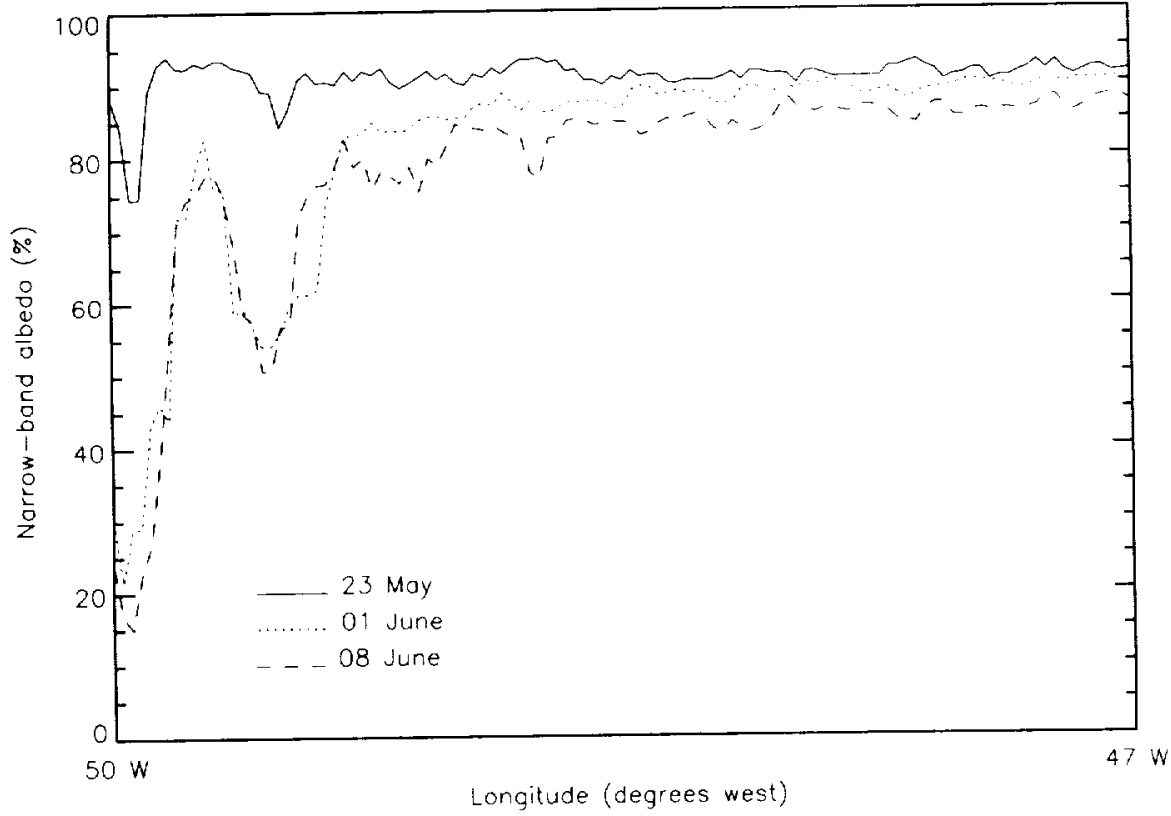

Fig. 7. Narrow-band surface albedo $(0.58-0.68 \mu \mathrm{m})$ time series showing the melt region at $69.6^{\prime \prime} \mathrm{N}$. The time series is from May 23, June 01 and June 08, 1991

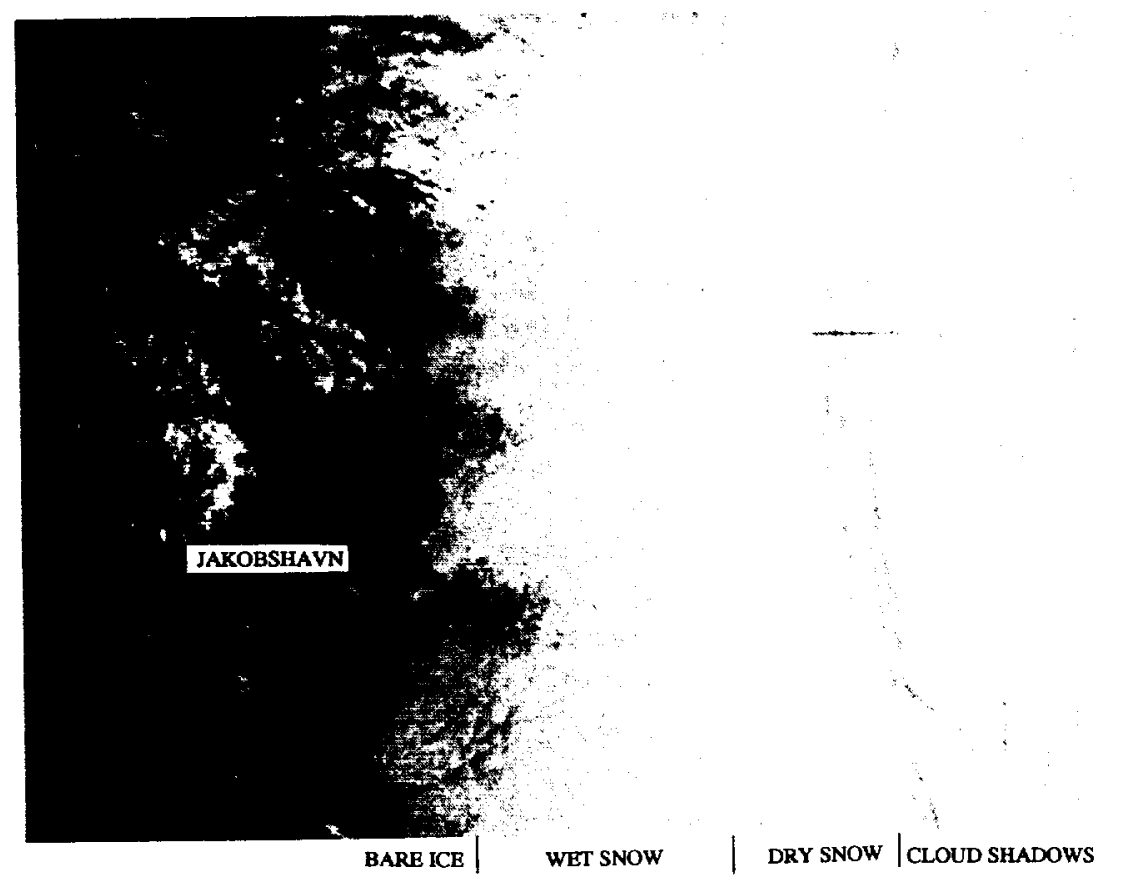

Fig. 8. AVHRR channel 1 imagery for the Jakobshvan area of the Greenland ice sheet, June 8, 1991. Location and size of this imagery is given in Fig. 1. Bare ice, wet snow, dry snow and cloud shadows can be identified by different gray levels (reflectance)
$90.2 \%$. A recent intercomparison with the same input values but using the LOWTRAN for the atmospheric correction gave a narrow-band albedo value of $93.3 \%$ (Haefliger et al., 1993). This preliminary analysis shows that with in situ atmospheric temperature and humidity profile data as input variables for the radiative transfer model, narrow-band surface albedo can be derived within one and two percent accuracy from AVHRR channel 1. Furthermore, the comparison suggests that the standard aerosol and ozone concentrations give reasonable results for this case study. However, comparisons for different seasons and a larger number of cases are needed to derive statistically significant values.

It should be noted that altitude dependence was not considered in these computations, as we were only interested in relative changes of the albedo. 
In order to derive narrow-band albedo maps of the entire Greenland ice sheet, this correction is essential. However, the discussion of albedo maps for the entire Greenland ice sheet is beyond the scope of this paper.

\subsection{Dry Snow/Wet Snow Classification}

The passive microwave brightness temperature $T_{b}$ is, according to Rayleigh-Jeans approximation, a product of the emissivity $\varepsilon$ and the mean physical temperature $T$ of the snow layer from which the radiation is emanating.

$T_{b}=\varepsilon T$.

Radiative transfer model calculations show that the penetration depth for dry snow depends mainly on snow density, the radius of the snow grains particles, and the physical temperature of the snow medium (Zwally, 1977). The penetration depth of passive microwave radiation is defined as the inverse of the extinction coefficient. It is a function of frequency, grain size, physical temperature of the snow layer, and density. According to Ulaby et al. (1986) the penetration depth (d) for snow can be approximated by:

$d=(\lambda / 2 \pi)\left(\sqrt{\varepsilon^{\prime} / \varepsilon^{\prime \prime}}\right)$,

where $\lambda$ is the wavelengths of the radiation in meters, $\varepsilon^{\prime}$ is the relative permittivity which is a constant for snow $\left(\varepsilon^{\prime}=3.15\right)$, and $\varepsilon^{\prime \prime}$ is the dielectric loss factor. The penetration depth was calculated according to Eq. 5, and the values are given in Table 3 for two frequencies and two different temperatures.

For melting snow, the penetration depth is strongly reduced by increasing liquid-water content in the snow pack. For wet snow the volume scattering is absent due to strongly reduced penetration, which leads to the near-black body emission, especially at vertical polarization (Mätzler and Hueppi, 1989). Thus it can be seen that the microwave emission emanates from different depths for different snow types (dry and wet snow). At frequencies above $20 \mathrm{GHz}$, scattering becomes the dominant component of the total extinction loss of the medium. This means that the emissivity of the snow depends strongly on the snow grain size, and increases with decreasing grain radius (Srivastav and Singh, 1991). Based on these theoretical considerations we would expect a large variation of the brightness temperature over the Greenland ice sheet which should yield information on the different snow facies associated with melt and accumulation rates.

Figure 9 shows a brightness temperature timesequence profile across Greenland from $310^{\circ}-$ $335^{\circ} \mathrm{E}$, at $69.6^{\circ} \mathrm{N}$ for the SSM/I $19 \mathrm{GHz}$ vertical polarization. The record is for January 13, 1988 through March 31, 1991 at a daily interval. The three main melting periods at the margins of the Greenland ice sheet are clearly shown in the graph. The brightness temperature increase is due to near black-body emissions of the wet snow cover. For the higher regions of the ice sheet between $320^{\circ}$ and $325^{\circ} \mathrm{E}$, where the air temperature is always below freezing (dry snow regions), the $T_{b}$ is quite constant. Figure 10 shows two selected brightness temperature cross sections to demonstrate the difference between the summer-melt condition and the winter condition. The profile consists of $33 \mathrm{SSM} / \mathrm{I}$ pixels $(25 \times 25 \mathrm{~km})$. The increase of the winter $T_{b}$ at the east coast of Greenland is due to the close proximity of land (spill-over) and can be explained by large $19 \mathrm{GHz}$ field of view $(69 \times 43 \mathrm{~km})$ binned to a $25 \times 25 \mathrm{~km}$ grid.

Equation 4 shows that $T_{b}$ is related to the physical temperature, which makes snow type classification based on a single channel impossible for large regions extending over different temperature regimes. The gradient ratio (GR) between

Table 3. Microwave Penetration Depths for Dry Snow with a Grain Size Radius of $r=0.5 \mathrm{~mm}$ at $19 \mathrm{GHz}$ and $37 \mathrm{GHz}$ for a Mean Snow Temperatures of $-1^{\circ} \mathrm{C}$ and $-20^{\circ} \mathrm{C}$

\begin{tabular}{|c|c|c|c|c|}
\hline Frequency & $\begin{array}{l}\text { Dielectric loss } \\
\text { factor at }-1{ }^{\circ} \mathrm{C}\end{array}$ & $\begin{array}{l}\text { Penetration } \\
\text { depth }(\mathrm{m})\end{array}$ & $\begin{array}{l}\text { Dielectric loss } \\
\text { at }-20^{\circ} \mathrm{C}\end{array}$ & $\begin{array}{l}\text { Penetration } \\
\text { depth (m) }\end{array}$ \\
\hline $\begin{array}{l}19 \mathrm{GHz} \\
37 \mathrm{GHz}\end{array}$ & $\begin{array}{l}6.8 \cdot 10^{-3} \\
2 \cdot 10^{-2}\end{array}$ & $\begin{array}{l}0.66 \\
0.10\end{array}$ & $\begin{array}{l}1.8 \cdot 10^{-3} \\
2.7 \cdot 10^{-3}\end{array}$ & $\begin{array}{l}2.5 \\
0.83\end{array}$ \\
\hline
\end{tabular}



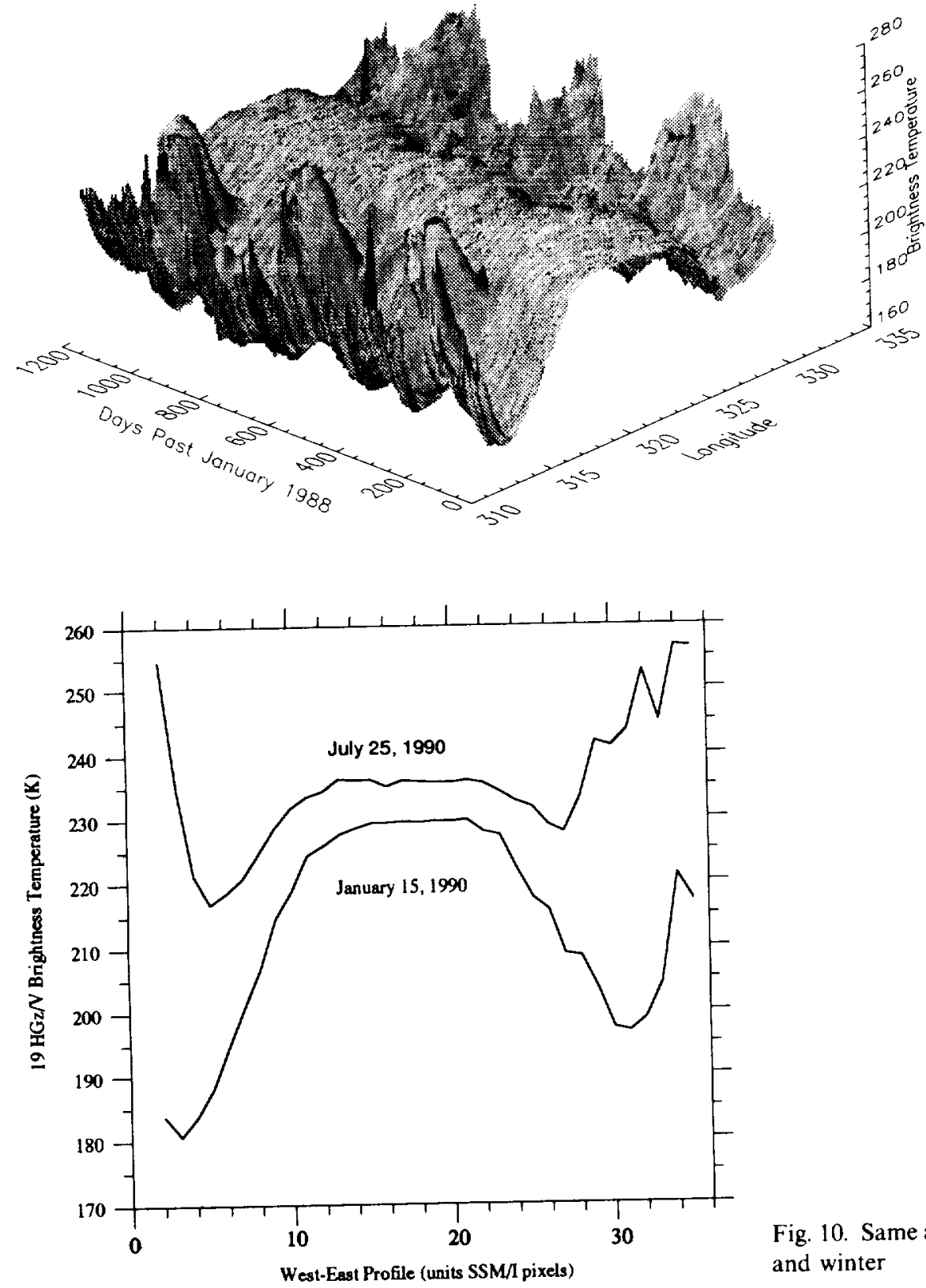

Fig. 9. Passive microwave brightness temperature time series across Greenland for $\mathrm{SSM} / \mathrm{I} 19 \mathrm{GHz}$ vertical polarization. The time series runs from January 1, 1988 through March 31,1991 . The dominant three peaks along the ice margins demonstrate the $T_{b}$ increase due to wet snow
Fig. 10. Same as Fig. 9 for two selected days in summer and winter
19 and $37 \mathrm{GHz}$ (Eq. 1) shown in Fig. 11 for three consecutive years at the ETH/CU station reduces the snow temperature dependence. These values were compared with automatic weather station data collected within $10 \mathrm{~km}$ of the station by the Geological Survey of Greenland (unpublished data, personal communication Henrik Thomsen, GGU). For all three years the sharp GR increases in spring (e.g. April 4, 1988) coincide in time with the air temperatures increases above the zero degree centigrade on the very same day. The sharp decreases of the GR value at the end of the summer (e.g. September 15, 1988) coincide also with sub-zero air temperature readings from the automatic weather station. The air temperature measurements from the $\mathrm{ETH} / \mathrm{CU}$ research station and the corresponding GR values as derived from the SSM/I satellite data are shown in Fig. 12. It is 


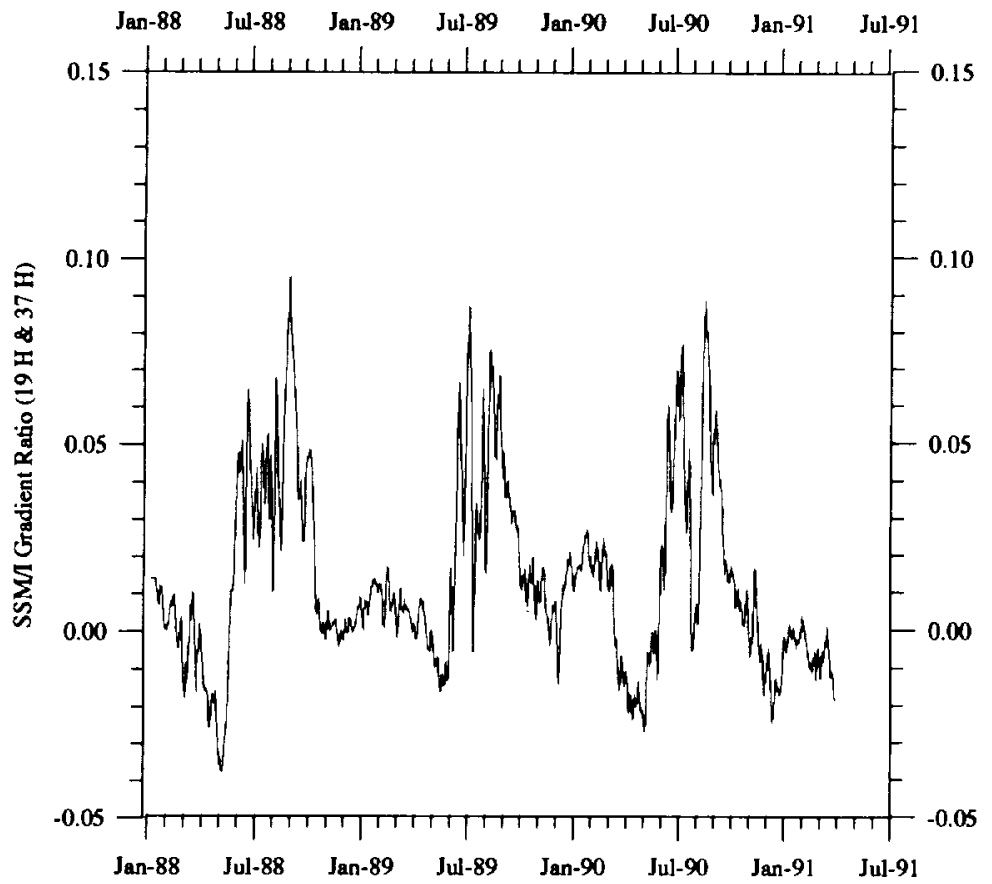

Fig. 11. SSM/I gradient ratio, $19 \mathrm{GHz}$ and $37 \mathrm{GHz}$ horizontal polarization, at the location of the ETH $\mathrm{CU}$ research station on the Greenland ice sheet from January 1988 through July 1991

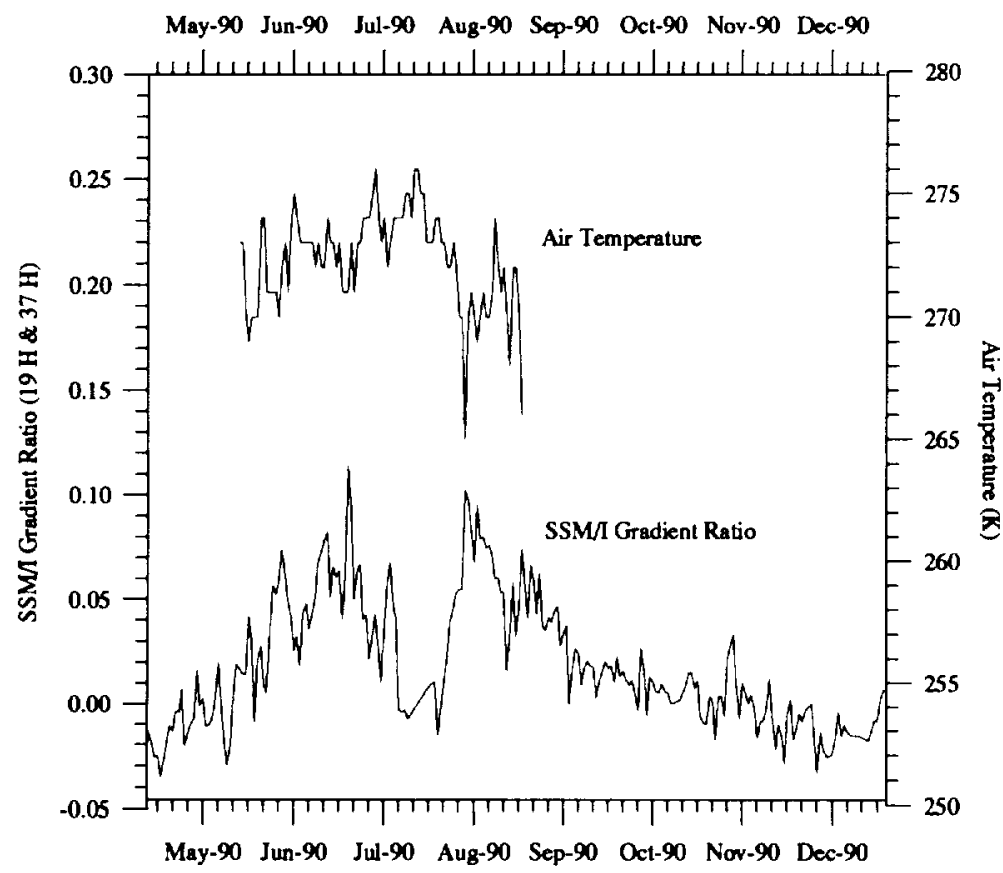

Fig. 12. SSM/I gradient ratio, $19 \mathrm{GHz}$ and $37 \mathrm{GHz}$ horizontal polarization, and air temperature at the location of the ETH/CU research station for summer 1990 rather surprising how well the air temperature correlates with the satellite measurements $(25 \times$ $25 \mathrm{~km}$ gridded data). The correlation is negative due to the different penetration depths of 19 and $37 \mathrm{GHz}$. An increase in surface temperature effects the $37 \mathrm{GHz}$ frequency more than the $19 \mathrm{GHz}$ frequency and consequently the GR value decreases.
The same response, but with negative sign, can be seen with a surface cooling.

The GR value seems to be a good classifier for the distinction between dry and wet snow. Since large GR fluctuations, caused by the temperature gradient change within the snow cover, are large we have averaged the GR value over 10 days for 

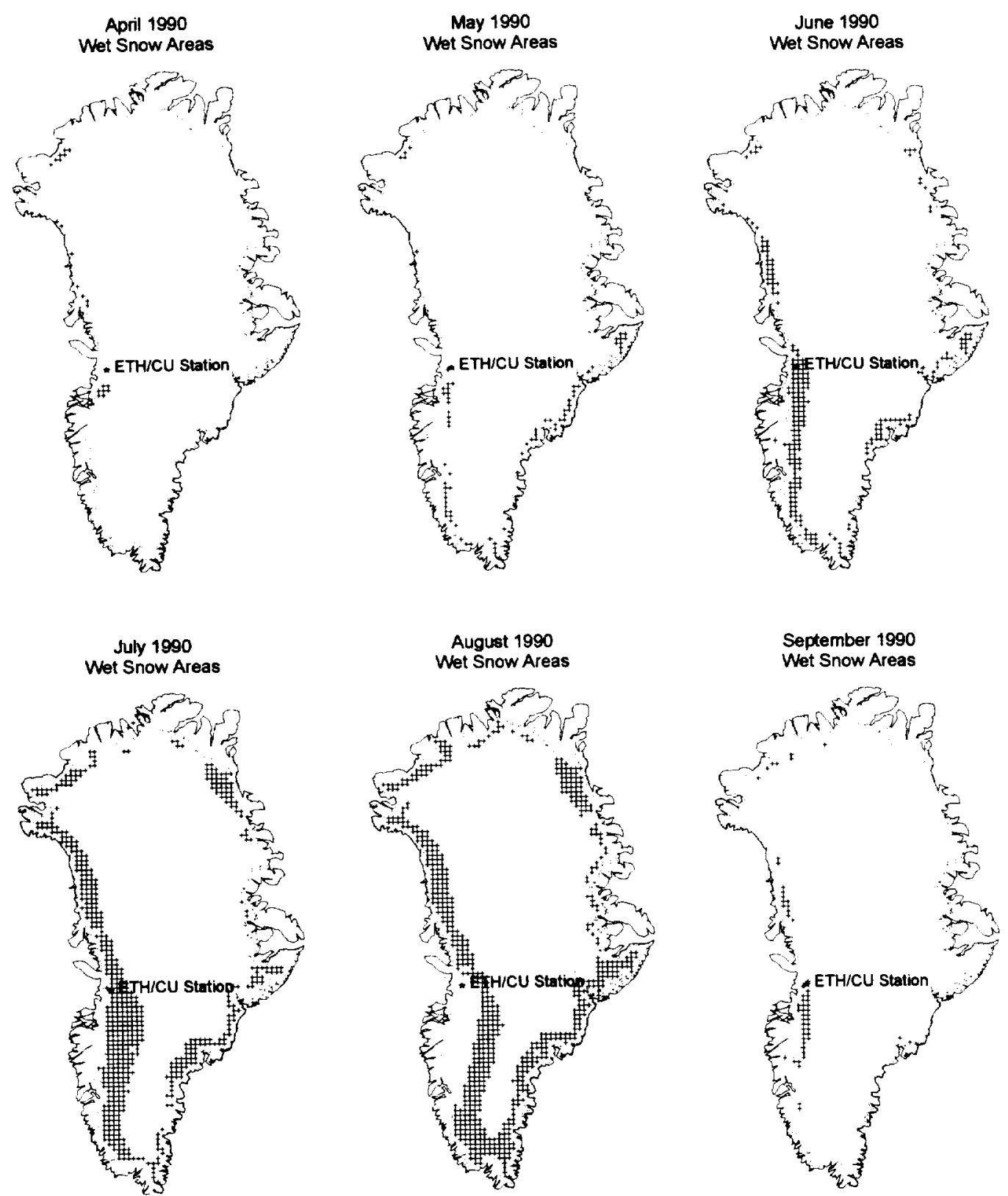

Fig. 13. Time sequence of wet snow areas as classified with gradient ratio threshold $(19$ and $37 \mathrm{GHz} / \mathrm{H})$ for each mid month period of April through September 1990 . Each pixel $(+)$ represent an area of $25 \times 25 \mathrm{~km}$

each month and used a threshold of GR $=+0.025$ to distinguish between dry and wet surface snow. In Fig. 13 we show the wet snow area of the entire Greenland ice sheet for each mid-month period of April through September, 1990. In April only a few wet snow signatures are classified along the west coast of Greenland. A very strong signal is observed at $80^{\circ} \mathrm{N}$ in the region of the Humboldt Glacier (see Fig. 1 for location). Melting at such high latitudes is questionable that early in the season; however, the close proximity of the North Water polynya, with air temperatures up to $8{ }^{\circ} \mathrm{C}$ above normal, could explain this early melting (Steffen, 1985). This melt signal is consistent throughout the following 4 months. In May the melt areas have extended along the margin of the ice sheet south of $70^{\circ} \mathrm{N}$. The southeast coast of the ice sheet shows little melting which could be an artifact of the large pixel footprint and the steeply rising ice sheet in those regions. In June 
and July the wet snow areas increase from $9 \%$ to $22 \%$ of the total ice area and reach the maximum extent of $26 \%$ in mid August. The gradient threshold method classifies wet snow areas, whereas glacier ice has a GR value close to zero. This explains the "unclassified" areas along the west coast in the vicinity of the $\mathrm{ETH} / \mathrm{CU}$ research camp for the August period. Local observations from helicopter flights in that region during August 1990 confirm this hypothesis (Ohmura et al., 1992). In September the wet snow areas are reduced to the region of the low ice margin as the new snow precipitation masks the melt signal.

\subsection{Passive Microwave Brightness Temperature Variations}

Additional time series of interest are those at different locations near the center of the ice sheet where the altitude is high, the snow is dry, and the region is the most homogeneous. Some interesting trends in brightness temperatures are found in some of these areas, and they are discussed below. At these locations, instead of extracting the observations by means of a transect and then a single pixel value (as in the case of the climate station), a $2 \times 2$ pixel region is filtered out of each image and
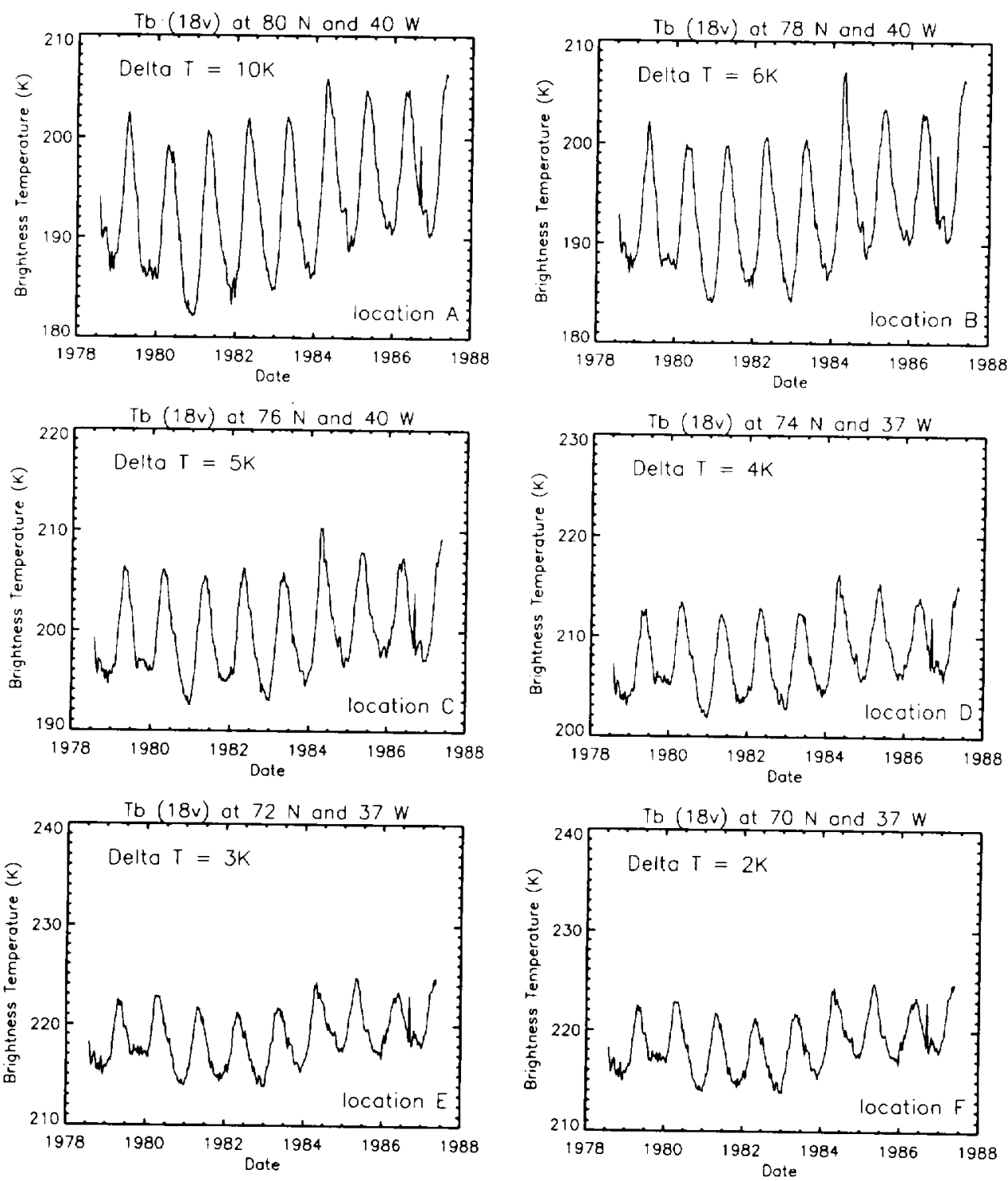

Fig. 14. Time series of brightness temperatures for the full period of SMMR coverage at different locations along the central ridge of the Greenland ice sheet (see Fig. 1, A-F) 

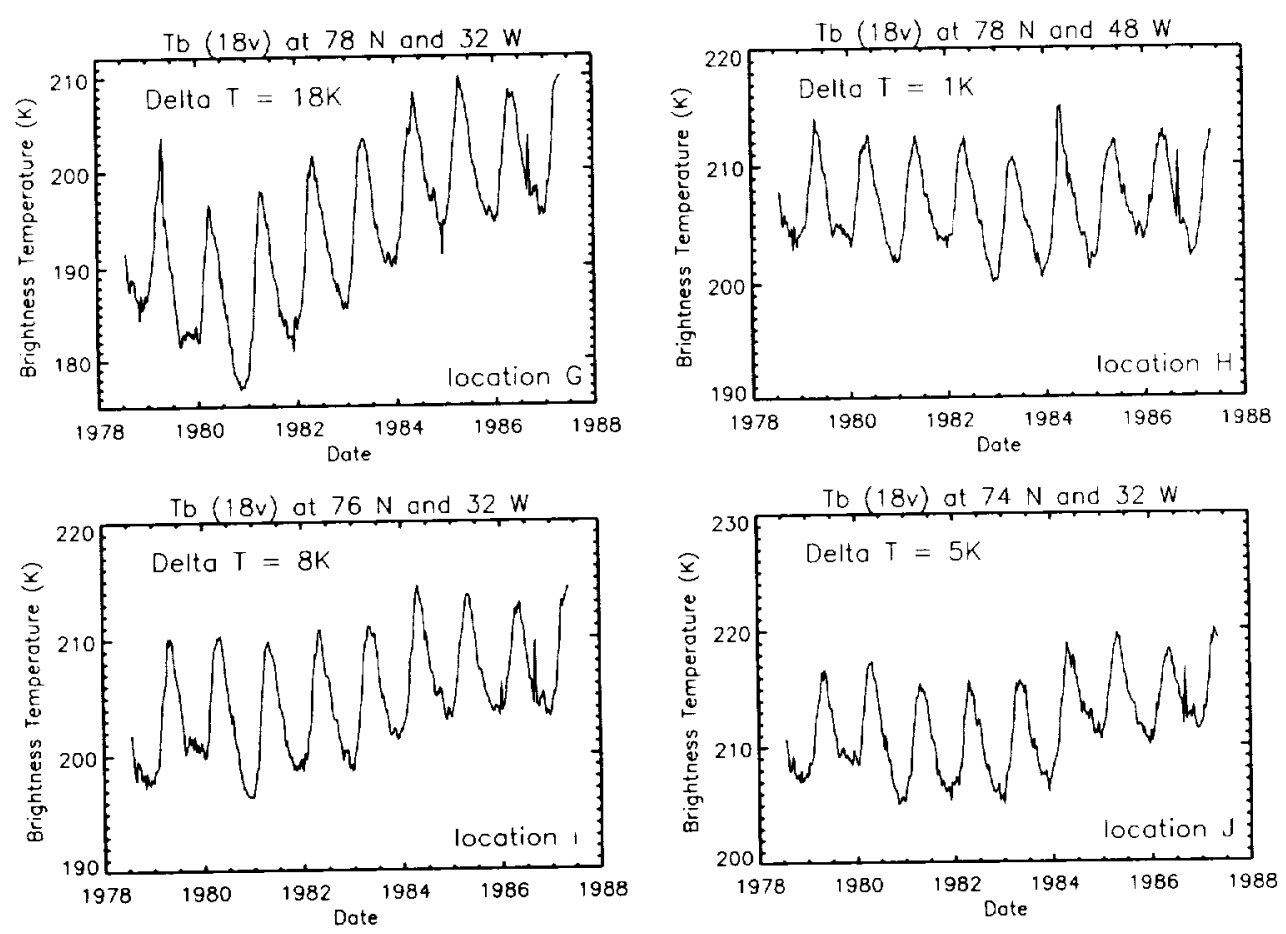

Fig. 15. Time series of brightness temperatures for the full period of SMMR coverage at different locations along the central ridge of the Greenland ice sheet, off of the central ridge (see Fig. 1, G-J)

is spatially averaged. In this way, localized anomalies are smoothed out.

The locations of the selected areas are shown in Fig. 1, and the corresponding time series of brightness temperatures from the SMMR $18 \mathrm{GHz}$ vertically polarized channel are shown in Figs. 14 and 15. The SMMR data set was selected over SSM/I because it spans a greater period of time. Ultimately, the two will be combined. Locations A through $F$ are chosen because they span the highest sections of the ice sheet for the given latitude. Effects due to melt are thus eliminated. Additional areas of the ice sheet were selected for broader comparisons, but not all are shown in the figures.

A trend is clearly evident in most of the plots between the winters of 1981 and 1986, with winter brightness temperature increases ranging from $1 \mathrm{~K}$ to nearly $20 \mathrm{~K}$ over the 5 year period. We believe the trend holds some information about climatological features for the various locations sampled. It may be due to changes in the physical temperature, variations in the snow accumulation rate, differences in snow grain sizes over those years, changes in snow depth, or a combination of variations in several of these features. Each can affect the brightness temperature.

\section{Grain Size}

The relationship between grain size and brightness temperature has been clearly demonstrated (Srivastav and Singh, 1991). As grain size increases, the $T_{b}$ also decreases. If there is snowfall in the region, the grain size depends on the atmospheric temperature and humidity, but should remain relatively constant due to wind action. The grain size of the snow underneath will increase due to snow metamorphosis (Seligman, 1980). If there is no accumulation, then snow metamorphosis will also cause grain size increase. In either case, the effect on brightness temperature will be a decrease, or no change. In fact, the only way grain size of new snow can increase the brightness temperature is by reducing in size. It is not likely that the observed $T_{b}$ increase over several years (Fig. $14 \mathrm{~A}$ ) is caused by reduction in grain size at the surface of the snow layer. The possibility that every year there is a constant decrease in temperature such that the grains become smaller and 
the brightness temperature consistently increase is minimal. Furthermore, the temperature and grain sizes are not correlated over a very broad range. For these reasons, the observed trend is not attributed to grain size changes.

\section{Physical Temperature}

It is possible that the observed trend may reflect a physical temperature rise since the two are directly proportional. However, there is no evidence of such a temperature increase from the nearby meteorological stations at the north-east coast of Greenland (Nord and Danmark Havn). In addition there is a large variation in the range of temperature increase from one location to another. The maximum occurs at $78^{\circ} \mathrm{N}$ and $32^{\circ} \mathrm{W}$, and it is $18 \mathrm{~K}$. At the same latitude, but at $48^{\circ} \mathrm{W}$ longitude, there is a minimal change of $1 \mathrm{~K}$. Furthermore, the regions south of $70^{\circ} \mathrm{N}$ seem to exhibit almost no apparent pattern. We would expect, if a rise in physical temperature were responsible for the observed brightness temperature increases, that the trends would be much more consistent throughout the ice sheet.

\section{Accumulation Rate}

An increase in accumulation rate results in an increase in emissivity (Zwally, 1977), which is directly proportional to brightness temperature. Therefore, it is possible, that the trends observed may be explained by changes in accumulation rate.

As stated in section 3.2, the penetration depth for the $19 \mathrm{GHz}$ vertical channel at $-20^{\circ} \mathrm{C}$ is $2.5 \mathrm{~m}$. Winter temperatures averaged from 1951 through 1960 were found to be $-40^{\circ} \mathrm{C}$ in the northeastern portion of the ice sheet (Ohmura, 1987), which is where the trend is strongest. There is no published dielectric loss factor for such a low temperature, but according to Eq. 5 , the penetration depth will be even greater than the $2.5 \mathrm{~m}$ calculated for $-20^{\circ} \mathrm{C}$.

For locations in which the mean accumulation rates are higher than the penetration depth during the winter season, snow accumulations do not support a sustained brightness temperature increase. For extreme cases in these areas, a year of very low accumulation might stand out as a drop in brightness temperature as the emissivity of larger subsurface grain sizes serves to reduce the signal. However, a trend of high accumulation rates in these areas over several years should only result in a rise in brightness temperatures for the first one or two years. After that time, the curve should level off as the signal contribution of the smaller grained new snow increases while the contribution of the old snow below diminishes.

On the other hand, if the mean accumulation rate is relatively low in comparison to the penetration depth, and there is always a significant contribution to the signal from old snow below the surface, then changes in accumulation rates should correspond directly to changes in brightness temperatures. High accumulation rates in these typically low rate regions will result in effectively smaller grain sizes being responsible for most of the signal, and will appear as an increase in $T_{b}$. Low accumulation rates will result in effectively larger grain sizes due to the strong contribution of the old snow below the new, and thus reduce the brightness temperatures. In these areas the sensitivity of $T_{b}$ varies inversely with the mean accumulation rate (Zwally, 1977), in other words lower accumulation rate corresponds to higher $T_{b}$ and visa versa.

Mean accumulation rates throughout the ice sheet were evaluated by Ohmura and Reeh (1991). Their findings indicate the lowest rates, on the order of $100-200 \mathrm{~mm}$ water equivalent annually, are characteristic of the northeast portion of the ice sheet. The brightness temperatures in this area should be most sensitive to accumulation, and they do in fact exhibit the strongest trends (Fig. $15 \mathrm{G}$ ). Conversely, the rest of the ice sheet, west of the divide, and also south of $70^{\circ} \mathrm{N}$ has high accumulation rates, and the corresponding brightness temperature trends are very small. Furthermore, the brightness temperature trends increased with higher latitude (see the temperature changes stated in Fig. 14), while coincidentally, the accumulation rates decreased.

The interannual variations in snow accumulation for $78^{\circ} \mathrm{N}$ and $32^{\circ} \mathrm{W}$ for 1979 through 1987 are qualitatively described in Table 4. Similar relationships can be determined for any other location in the sensitive northeast region.

\section{Snow Depth}

The argument for snow depth is similar to that for accumulation rate. Deep snow on the ice, which 


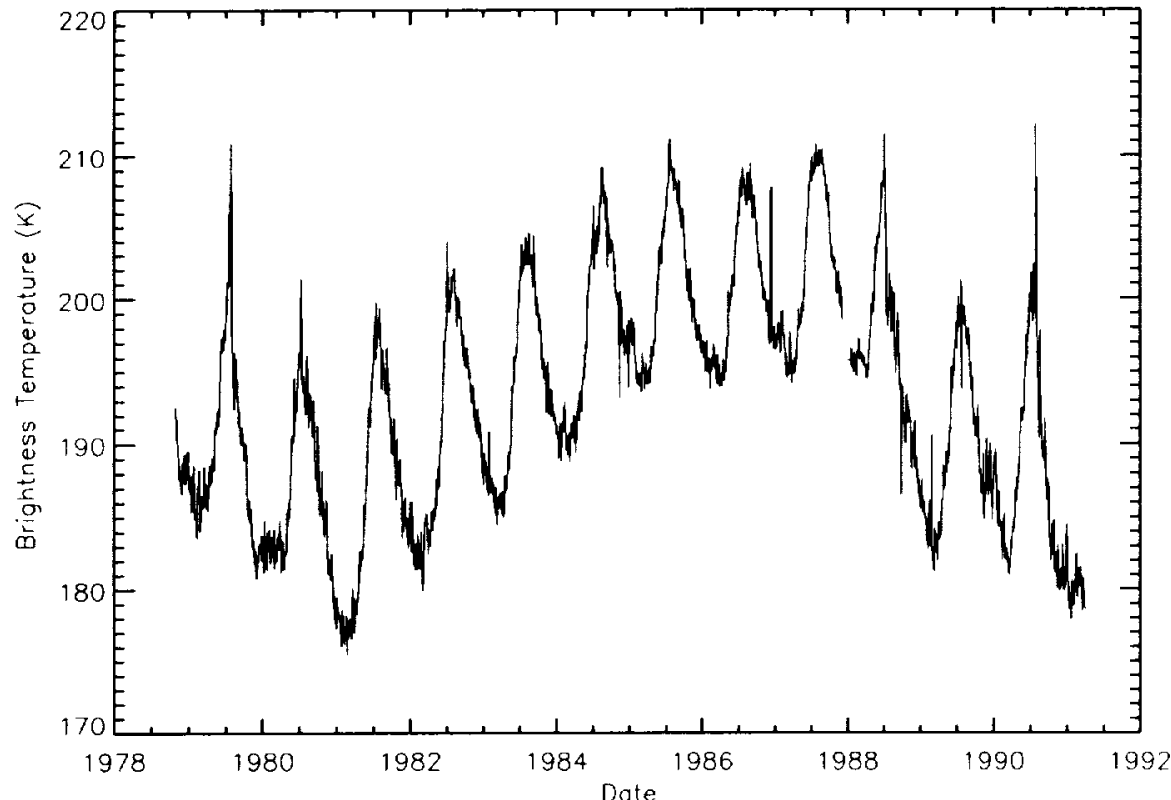

Fig. 16. Combined time series of SMMR and SSM/1 data at $78^{\circ} \mathrm{N}$ latitude and $32^{\circ} \mathrm{W}$ longitude. The offset between the two data sets was corrected according to the linear fit given in Fig. 4
Table 4. Relative Accumulation Rates at $78^{\circ} \mathrm{N}$ and $32^{\circ} \mathrm{W}$ (NE Greenland) for 1979 Through 1987 as Determined from Fig. 15

\begin{tabular}{ll}
\hline Year & Comparison to previous year \\
\hline 1979 & less accumulation \\
1980 & less accumulation \\
1981 & less accumulation (least of all) \\
1982 & more accumulation \\
1983 & more accumulation \\
1984 & more accumulation \\
1985 & more accumulation \\
1986 & about the same accumulation \\
1987 & same accumulation \\
\hline
\end{tabular}

results from high accumulation rates, exhibits a higher brightness temperature than shallow snow at the same physical temperature. The reason is that old subsurface snow from previous years will contribute less to the microwave signal if the accumulation rate is high. As with accumulation rate, the relationship is only significant in regions where the depth of new snow is less than the penetration depth of passive microwave radiation.

Figure 16 shows a comprehensive time set of $18 \mathrm{GHz}$ vertically polarized SMMR data and $19 \mathrm{GHz}$ vertically polarized $\mathrm{SSM} / \mathrm{I}$ data. Due to overheating, the SSM/I sensor was shut off during the winter of 1987 , and consequently there is a two month gap in the data. The SSM/I data were adjusted according to our regression coefficients displayed in Fig. 4. As with the SMMR data, interannual changes in the brightness temperature are apparent in the region with a low snow accumulation rate. A decrease in accumulation rate during the period of $S S M / I$ coverage is indicated by the decrease in brightness temperature.

\section{Conclusion}

Little difference between the lower and higher resolution AVHRR data is seen for regions of dry snow, melt areas, and clouds. Therefore, Global Area Coverage (GAC) data can be used for long-term snow surface albedo studies over most of the Greenland ice sheet. Local Area Coverage (LAC) data is found to be necessary during transitional periods in the spring, and thus, is needed for studies of the onset of melt.

Small albedo changes of a few percent can be detected, which enables us to classify different snow types in conjunction with ground based spectral measurements. For absolute albedo determination, in situ radiosonde, ozone, and aerosol measurements are required for input into radiative transfer models. In addition, a digital elevation model is needed to correct for the changes in atmospheric path length over the ice sheet. 
There is a distinct passive microwave signal of melting, which can be used to classify wet snow areas and identify the onset of melt. This is accomplished by using a gradient ratio threshold of SSM/1 $19 \mathrm{GHz}$ and $37 \mathrm{GHz}$ horizontal polarization. The seasonal change of wet snow extend was analyzed for the months May through September, 1990. Wet snow areas are generally larger on the west side of the ice sheet due to lower topography and consequently higher air temperatures. The maximum wet snow extent of $26 \%$ of the total ice area was found in August. The bare ice areas of the margins, where the seasonal snow cover has disappeared, are not included in this statistics.

Many features within the snow pack contribute to variations in brightness temperature. These can be attributed to real physical changes that are important for climate sensitivity studies. The issue is further complicated by variations of penetration depth of the two frequencies used. A better understanding of the physical processes, as well as in situ data are needed in order to more accurately identify and quantify those features.

However, the evidence does suggest that in some regions of the ice sheet, relative or qualitative statements can be made about the rate of accumulation. This is very encouraging since there is not yet an accurate method for quantifying snow cover over ice (most of the algorithms to date deal with snow over land). The accumulation increase as detected for the north-eastern part of Greenland during 1981 through 1986 is in general agreement with average ice-sheet surface elevation changes for the southern part of Greenland as reported by Zwally (1989). More work needs to be done before such quantitative statements about the snow accumulation can be made, but is does appear to be feasible.

While snow typing is easily accomplished with AVHRR data during clear sky conditions, it is still limited by cloud cover. This limitation can be overcome by using passive microwave data, whose signal penetrates clouds. However, passive microwave data is limited by its coarse spatial resolution; thus, important sub-pixel phenomena cannot be resolved. A combination of the two data sets seems promising and will yield a more complete description of surface conditions than can be obtained by each individually.

\section{Acknowledgements}

This research was supported under contract NAGW-2158 by NASA Ocean Science Branch, by the Swiss Federal Institute of Technology (ETH), Zurich (Grant Nos. 0-20-004-90, $04-040-90,0-15-03-90,0-15-080-90,0-15-150-90$ ) and the Swiss National Foundation for Scientific Research (Grant No. 21-27449.89). Provision of computing resources by the Syracuse University Academic Computing Services during the leave of absence (W. A.) is acknowledged. The passive microwave satellite data were provided by the National Snow and Ice Data Center (NSIDC), in Boulder Colorado.

\section{References}

Ambach, W., Kuhn, M., 1985: The shift of equilibrium line altitude on the Greenland Ice Sheet following climatic changes. In: Meier, M. et al. (eds.) Glaciers, Ice Sheets, and Sea Level: Effects on $\mathrm{CO}_{2}$-Induced Climatic Change. U.S. Dept. of Energy. Washington, D.C., 255-257.

Baldwin, D., Emery, W. J., 1993: A systematic approach to AVHRR image navigation. Annals of Glaciology, 17 (in press).

Budyko, M. T., 1974: Climate and Life. New York, London: Academic Press

Chapman, W. L., Walsh, J. E., 1993: Recent variations of sea ice and air temperature in high latitudes. Bull. Amer. Meteor. Soc., 74(1), 33-47.

Dickinson, R. E., Meehl, G. A., Washington, W. M., 1987: Ice-albedo feedback in a $\mathrm{CO}_{2}$-doubling simulation. Climate Change, 10, 241-248.

Haefliger, M., Steffen, K., Fowler, C., 1993: AVHRR surface temperature and narrow-band albedo comparison with ground measurements for the Greenland ice sheet. Annals of Glaciology, 17 (in press).

Jezek, K. C., Merry, C., Cavalieri, D., Grace, S., Bedner, J., Wilson, D., Lampkin, D., 1991: Comparison between SMMR and SSM/I passive microwave data collected over the Antarctic ice sheet. Byrd Polar Research Center Technical Report No. 91-03, The Ohio State University, Columbus.

Kidwell, K. B., 1991: NOAA Polar Orbiter Data Users Guide. NOAA Information Service and Climate Data Center, Satellite Data Service Division, Washington D.C.

Koepke, P., 1989: Removal of atmospheric effects from AVHRR albedos. J. Appl. Meteor., 28, 13411348.

Lindsay, R., Rothrock, D., 1993: The calculation of surface temperature and albedo of Arctic sea ice from AVHRR. Annals Glaciolo., 17 (in press).

Manabe, S., Spelman, M. J., Stouffer, R. J., 1992: Transient responses of a coupled ocean-atmosphere model to gradual changes of atmospheric $\mathrm{CO}_{2}$. Part II: Seasonal response. $J$. Climate, 5, 105-126.

Mätzler, C. H., Huppi, R., 1989: Review of signature studies for microwave remote sensing of snowpacks. Adt. Space Research, 9(1), 253-265

Ohmura, A., 1987: New temperature distribution maps for Greenland. Zeitschrift fur Gletscherkunde and Glaziologie. 23(1), $1-45$.

Ohmura, A., Reeh, N., 1991: New precipitation and accumulation maps for Greenland. J. Glaciol., 37(125), 140-148. 
Ohmura, A., Steffen, K., Blatter, H., Greuell, W. G., Rotach, M., Konzelmann, T., Laternser, M., Ouchi, A., Steiger, D., 1991: Progress Report I: Energy and mass balance during melt season at the equilibrium line altitude, Paakitsoq, Greenland ice sheet. Dept. of Geography ETH-Zurich, Switzerland.

Ohmura, A., Steffen, K., Blatter, H., Greuell, W. G., Rotach, M., Stober, M., Konzelmann, T., Forrer, J., Ouchi, A., Steiger, D., Niederbaumer, G., 1992: Progress Report II: Energy and mass balance during melt season at the equilibrium line altitude, Paakitsoq, Greenland ice sheet. Dept. of Geography, ETH-Zurich, Switzerland.

Royer, A., O'Neill, N. T., Davis, A., Hubert, L., 1988: Comparison of radiative transfer models used to determine atmospheric optical parameters from space. Pro. SPIE, 928 , 118-135.

Steffen, K., 1985: Warm Water cells in the North water, northern Baffin Bay during winter. J. Geophys. Res. 90(C5), 9129-9136.

Steffen, K., Bindschadler, R., Comiso, J., Eppler, D., Fetterer, F., Hawkins, J., Key, J., Rothrock, D., Thomas, R., Weaver, R., 1993: Snow and ice applications of AVHRR in polar regions. Annals of Glaciology, 17 (in press).

Seligman, G., 1980: Snow Structure and Ski Fields. Cambridge: Foister \& Jagg LTD.

Srivastav, S. K., Singh, R. P., 1991: Microwave radiometry of snow covered terrains. J. Remote Sens., 12(10), 2117 2131.

Tanre, D., Deroo, C., Duhaut, P., 1990: Description of a computer code to simulate the satellite signal in the solar spectrum: the 5S code. Int. J. Remote. Sens., 11, 659-688.

Teillet, P. M., 1992: An algorithm for the radiometric and atmospheric correction of AVHRR data in the solar reflective channels. Rem. Sens. Environ., 41, 185-195.

Ulaby, F. T., Moore, R. K., Fung, A. K., 1986: Microwave Remote Sensing: Active and Passive, Vol. III. Norwood: Artech House.

Williams, R. S., Hall, D. K., Benson, C., 1991: Analysis of glacier facies using satellite techniques. J. Glaciology. $37(125), 120 \quad 128$.

Zwally, J., 1977: Microwave emissivity and accumulation rate of polar firn. J. Glaciology. 18(79), 195 216.

Zwally, J., 1989: Growth of Greenland ice sheet: Interpretation Science, 246, 1589-1591.

Authors' address: K. Steffen, W. Abdalati and J. Stroeve, Cooperative Institute for Research in Environmental Sciences, Campus Box 216, University of Colorado, Boulder, CO 80309, U.S.A. Email: Koni@seaice.colorado. edu, Telemail: K. Steffen. 